\title{
Pululima faifai pea: Establishment of Samoan immersion early childhood education centres and bilingual units in primary and intermediate
}

\section{Patisepa Tuafuti}

\begin{abstract}
Sāmoan Immersion Preschools (A'’oga 'Amata) and Bilingual Education units covering from year one to year eight of school have become well established in some areas in the Auckland region since the 1980s, due to the commitment, support and contributions of parents, the Sāmoan community, church leaders, families and some schools. Given that parents, families and communities appeared to have played such a seminal role in their establishment, this research was set out to investigate Sāmoan parents' lived experiences in relation to the establishment of ā'oga 'amata and Sāmoan bilingual education units. Fa'afaletui phenomenology, a term I developed in the process of conducting the research, was employed as a culturally appropriate coupling methodology. Phenomenology is about lived experiences and fa'afaletui is a process and procedure of revealing participants' lived experiences. Insights into parents' lived experiences were obtained by using various methods namely: questionnaire, focus group discussions, individual interviews, couple interviews and testimonies. The lived experiences were collated from the recounts of past events. The recounts were analysed for themes, which arose from the comments and interpretations of the past events, and the expressions of emotions attached to the events. Observations and analyses of past events highlight many challenges that the participants experienced. Challenges ranged from financial difficulties and lack of resources, to lack of understanding about bilingual/immersion education. What the results make clear is the resilience of the participants in defending what they believe is right as far as fa'asāmoa is concerned, and the powerful role of emotions in personal and educational lives. Resilience and emotions are coefficients in the results and they have theoretical importance in understanding the research findings.
\end{abstract}

Wilf Malcolm Institute of Educational Research, Faculty of Education, University of Waikato, Hamilton, New Zealand ISSN: 2382-0373

Permanent Research Commons link to full thesis:

researchcommons.waikato.ac.nz/bitstream/handle/10289/10683/thesis.pdf? sequence $=4$

(p. 117) 